\title{
Percepção discente sobre os conteúdos essenciais de Ciências Sociais em Saúde Bucal em uma graduação em odontologia
}

\author{
Leonardo Carnut, Samylla Glória de Araújo Costa, José Gomes de Moura Neto
}

\begin{abstract}
Resumo
Atribuir sentido ao estudo das Ciências Sociais nos estudantes dos cursos odontológicos tem sido um desafio. Tradicionalmente, há um apelo para o tema do 'esgotamento da prática odontológica à luz do modelo biomédico' e, por consequência, a importância do cirurgião-dentista com perfil crítico-humanista. Entretanto, raramente as ciências sociais é solicitada para produzir uma reflexão profunda a respeito do "objeto" da odontologia, e por conseguinte, questionar seu estatuto de cientificidade. Assim, este estudo preocupou-se em trabalhar a percepção discente sobre quais seriam os "principais conteúdos" sobre 'ciências sociais em saúde bucal' que versam sobre a crítica à odontologia enquanto ciência e suas fases de produção científica. Para isso, realizou-se uma pesquisa-ação do tipo crítico-colaborativa. Foi proposta para os sujeitos a produção de resumos (como forma de avaliação processual) sobre dois textos que tratavam do assunto em tela. O cenário de intervenção foi o componente curricular 'Saúde Coletiva II' da Universidade de Pernambuco Campus Arcoverde, ministrado no segundo período do curso com 18 estudantes participantes como sujeitos. Foi-lhes solicitada a produção de 2 resumos para cada um dos estudantes sobre: a) a cárie dentária como fetiche na perspectiva de Botazzo (que trata da crítica ao 'espaço odontológico' e sobre a consolidação histórica da odontologia enquanto profissão autônoma) e b) 'odontologização' da odontologia na perspectiva de Freitas (que trata do percurso histórico da produção do conhecimento odontológico). A partir desse exercício, os estudantes retiravam do texto o conteúdo que mais lhes pareciam essenciais para descrever/sintetizar a ideia central dos textos que haviam lido. Para a técnica de análise dos textos foi utilizada a Análise de Conteúdo Clássica, do tipo frequencial, tomando-se os parágrafos como Unidade de Textual (UT) de análise. A partir daí, identificou-se as ideias centrais de cada parágrafo e procedeu-se a categorização das ideias por semelhança de conteúdo, considerando-se que todas as ideias centrais que emergiam nos resumos eram o conteúdo essencial sobre os temas segundo a percepção discente. Obteve-se ao total 27 resumos, donde 13 foram relativos ao primeiro tema e 14 ao segundo. Sobre o primeiro tema, foram identificadas 59 ideias agregadas em 15 categorias cujas mais frequentes foram: 40,6\% (24) 'surgimento sócio-histórico da odontologia'; 18,6\% (11) 'concepções sobre a cárie dentária' e $10,1 \%$ (6) 'perspectiva reformista da profissão odontológica'. Sobre o segundo tema, foram identificadas 64 ideias agregadas em 9 categorias cujas mais frequentes foram: 37,5\% (24) 'desenvolvimento dos estudos epidemiológicos sobre cárie dentária'; 29,6\% (19) 'conceito biologizado de cárie dentária' e 15,6\% (10) 'referência a pelo menos um dos termos "odontologização", "epidemiologização" ou "sociologização" '. Concluiu-se com estes achados, que a percepção discente considera o surgimento socio-histórico da odontologia e o desenvolvimento dos estudos epidemiológicos como conteúdos essenciais sobre os temas de 'ciências sociais em saúde bucal' estudados. É provável que, focando-se nesses conteúdos, seja possível (re)construir algum sentido no estudo das ciências sociais para esses estudantes que sirva para reflexão sobre o status quo da odontologia enquanto ciência.
\end{abstract}

Descritores: Educação Odontológica; Educação Superior; Ciências Sociais. 